\title{
Mechanisms of the breathing contribution to bodily self- consciousness in healthy humans: Lessons from machine-assisted breathing?
}

\author{
Sophie Betka $^{1}$ (D) | Elisa Canzoneri ${ }^{1}$ | Dan Adler $^{2}$ | Bruno Herbelin $^{1}$ | \\ Javier Bello-Ruiz $^{1}$ ｜ Oliver Alan Kannape ${ }^{1}$ | Thomas Similowski ${ }^{3,4}$ | Olaf Blanke ${ }^{1,5}$
}

\author{
${ }^{1}$ Laboratory of Cognitive Neuroscience, \\ Center for Neuroprosthetics \& Brain Mind \\ Institute, Ecole Polytechnique Fédérale de \\ Lausanne, Geneva, Switzerland \\ ${ }^{2}$ Division of Pulmonary Diseases, Geneva \\ University Hospital, Geneva, Switzerland \\ ${ }^{3}$ UMRS1158 Neurophysiologie Respiratoire \\ Expérimentale et Clinique, INSERM, \\ Sorbonne Université, Paris, France \\ ${ }^{4}$ Département R3S, Service de \\ Pneumologie, Médecine Intensive et \\ Réanimation, AP-HP, Groupe Hospitalier \\ Pitié-Salpêtrière Charles Foix, Paris, France \\ ${ }^{5}$ Department of Clinical Neurosciences, \\ Geneva University Hospital, Geneva, \\ Switzerland
}

\section{Correspondence}

Olaf Blanke, Laboratory of Cognitive Neuroscience, Center for Neuroprosthetics $\&$ Brain Mind Institute, Ecole Polytechnique Fédérale de Lausanne, Geneva, Switzerland.

Email: olaf.blanke@epfl.ch

Funding information

Bertarelli Foundation

\begin{abstract}
Previous studies investigated bodily self-consciousness (BSC) by experimentally exposing subjects to multisensory conflicts (i.e., visuo-tactile, audio-tactile, visuocardiac) in virtual reality (VR) that involve the participant's torso in a paradigm known as the full-body illusion (FBI). Using a modified FBI paradigm, we found that synchrony of visuo-respiratory stimulation (i.e., a flashing outline surrounding an avatar in VR; the flash intensity depending on breathing), is also able to modulate BSC by increasing self-location and breathing agency toward the virtual body. Our aim was to investigate such visuo-respiratory effects and determine whether respiratory motor commands contributes to BSC, using non-invasive mechanical ventilation (i.e., machine-delivered breathing). Seventeen healthy participants took part in a visuo-respiratory FBI paradigm and performed the FBI during two breathing conditions: (a) "active breathing" (i.e., participants actively initiate machine-delivered breaths) and (b) "passive breathing" (i.e., breaths' timing was determined by the machine). Respiration rate, tidal volume, and their variability were recorded. In line with previous results, participants experienced subjective changes in self-location, breathing agency, and self-identification toward the avatar's body, when presented with synchronous visuo-respiratory stimulation. Moreover, drift in self-location was reduced and tidal volume variability were increased by asynchronous visuorespiratory stimulations. Such effects were not modulated by breathing control manipulations. Our results extend previous FBI findings showing that visuo-respiratory stimulation affects BSC, independently from breathing motor command initiation. Also, variability of respiratory parameters was influenced by visuo-respiratory feedback and might reduce breathing discomfort. Further exploration of such findings might inform the development of respiratory therapeutic tools using VR in patients.
\end{abstract}

K E Y W O R D S

interoception, motor command, multisensory perception, pneumology, respiration, self 


\section{1 | INTRODUCTION}

Breathing-related signals belong to the array of bodily signals that contribute to bodily self-consciousness (BSC) (Adler, Herbelin, Similowski, \& Blanke, 2014; Allard et al., 2017; Monti, Porciello, Tieri, \& Aglioti, 2020), namely the feeling that conscious experiences are bound to a self that is localized within a body and grounded in perceptual multisensory brain mechanisms (Blanke, 2012; Blanke, Slater, \& Serino, 2015; Tsakiris, 2010). BSC has been shown to be based on exteroceptive (tactile, visual, vestibular, auditory) (Blanke, 2012; Ehrsson, 2012) and interoceptive signals (Aspell et al., 2013; Park et al., 2016, 2018; Suzuki, Garfinkel, Critchley, \& Seth, 2013), likely forming an integrated single system for BSC (Park \& Blanke, 2019). Manipulations of multisensory bodily signals have been shown induce altered states of BSC such as misperception of self-identification ("I felt as if the virtual body was my body") and self-location ("It seemed as if I was feeling my respiration in the virtual body"). Generally, during the full-body illusion (FBI) paradigm, a person watches a virtual body ("avatar") being stroked on the back in synchrony while receiving herself stroking at the same bodily location. Participants report relocation of the self toward the avatar and a feeling of ownership of the avatar (Ehrsson, 2007; Lenggenhager, Tadi, Metzinger, \& Blanke, 2007).

The same phenomena occur when viewing an avatar flashing in synchrony with heartbeats (Aspell et al., 2013). In the visuo-respiratory FBI, a flashing outline is surrounding the avatar and the intensity of the flash depends on the breathing signal of the participant. In the synchronous condition, the flash intensity is maximal during the participant's inspiration peak and is minimal during the participant's expiration trough, favoring multisensory integration, and embodiment of the avatar. In the asynchronous condition, the flash intensity pattern is following a faster or slower version of the participant's breathing, and thus, leads to incongruent multisensory information and reduced avatar embodiment (Adler et al., 2014; Allard et al., 2017). In this paradigm, we previously showed that respiratory visual synchrony induces not only changes in self-location and self-identification, but also changes in breathing agency (the feeling of controlling the act of breathing) (Adler et al., 2014; Allard et al., 2017). Thus, subjects seeing their avatar flashing in synchrony with their own breathing experienced sensations that the avatar "was breathing with them" and "used their lungs to breathe." The sense of agency has been proposed to emerge from both the initiation of an action, and a match between the predicted sensory feedback (which is inferred from the efference copy of the motor command, generated by motor areas and termed "corollary discharge") and the actual sensory feedback of the action (Blakemore, Wolpert, \& Frith, 2000; Daprati \& Sirigu, 2002; Haggard, 2017).
As other visceral functions, breathing is associated with a rich afferent signaling toward the brain, with the particularity that it conveys both interoceptive and exteroceptive information (Burki \& Lee, 2010; Davenport \& Vovk, 2009). Yet, in contrast to other visceral functions, breathing also involves motor commands generated in the central nervous system and that arise from both a brainstem driven automatic control and a cortex driven voluntary control (Adler \& Janssens, 2019; Colebatch et al., 1991; Foerster, 1936; Haouzi \& Bell, 2009; Haouzi, Chenuel, \& Barroche, 2006; Pouget et al., 2018). From an interoceptive point of view, these motor commands are thought to be integrated with respiratory afferents according to a corollary discharge mechanism (Buchanan \& Richerson, 2009; Killian, Gandevia, Summers, \& Campbell, 1984), comparable to control mechanisms of other movements. The relative roles of respiratory afferents and respiratory motor commands into the respiratory contribution to $\mathrm{BSC}$, however, are unknown. Of importance, the very notion of corollary discharge is currently considered central to the pathogenesis of dyspnea/breathing discomfort. Indeed, dyspnea is considered to result from an imbalance between the neural drive to breathe as a whole (combined brainstem and cortical respiratory commands) and the respiratory afferent traffic to the brain (Parshall et al., 2012).

Based on this, the specific aim of the present study was to determine whether or not the respiratory motor command contributes to BSC, especially breathing agency. We subjected healthy participants to non-invasive mechanical ventilation (NIV) through a facemask and tested the hypothesis that the effect of visuo-respiratory stimulation would differ during "active breathing" (where participants actively initiate machine-delivered breaths, likely associated with an efferent copy of the breathing motor command) versus "passive breathing" (where the respiration rate is solely determined by the machine, and not associated with an efferent copy of the breathing motor command). We further recorded respiratory parameters and their variability during the experimental manipulation of BSC. Indeed, breathing exhibits mathematical complexity (Fiamma et al., 2007) that stems from respiratory central pattern generators (Mangin et al., 2008; Ranohavimparany, Bautin, Fiamma, Similowski, \& Straus, 2016) and results in breath-by-breath variability, which give information pertinent to respiratory status (Schmidt et al., 2010; Teulier, Fiamma, Straus, \& Similowski, 2013; Tobin, Mador, Guenther, Lodato, \& Sackner, 1988; Wysocki et al., 2006). Finally, experimental and clinical situations associated with reduced breathing variability are also associated with dyspnea/respiratory discomfort (Preas et al., 2001; Wysocki, Meshaka, Richard, \& Similowski, 2004), possibly through an impoverishment of the respiratory afferent traffic to the brain that could contribute to a dyspnea generating sensorimotor imbalance (see above, Parshall et al., 2012). Accordingly, we 
also hypothesized that if respiratory motor commands contribute to the effects of visuo-respiratory synchrony on BSC, reducing the neural drive to breathe through machine-assisted breathing ("passive breathing") would modulate these effects.

\section{2 | METHOD}

\section{1 | Participants}

Seventeen healthy subjects (female: $N=10$; age: Mean $\pm S D$ $=24 \pm 3.6$ years; Median $=24 ; I Q R=4 ;$ range $=18-32$ ) participated in the experiment (Details regarding sample size calculation are provided in section 1 of the Supporting Information). All subjects had normal or corrected to normal vision and no history of psychiatric, neurologic, or lung diseases. The subjects received detailed information about the methods used and gave their written consent to participate. The study protocol was approved by the local ethics research committee at the University of Lausanne, Switzerland and was performed in accordance with the ethical standards of the Declaration of Helsinki.

\subsection{Experimental setup}

The present protocol was based on an experimental setup that has been used previously by our group to study BSC based on respiratory-visual stimulation (Adler et al., 2014; Allard et al., 2017); for related cardio-visual paradigms see (Aspell et al., 2013; Ronchi et al., 2015). Participants were asked to wear a Head-Mounted Display (HMD) and were lying on their back while watching a virtual scene projected in real time in the HMD (Figure 1). The scene consisted of a pulsating flashing outline surrounding a representation of the body of the subjects (Figure 1c). The critical manipulation was that the flashing was produced either synchronously or asynchronously with subjects' inspiratory efforts.

Inspiratory efforts (i.e., breaths) were monitored by using a belt mounted linear transducer (Pneumotrace ${ }^{\mathrm{TM}}$, Morro Bay, California), tightened at the level of the umbilicus at the end of a relaxed expiration, in terms of the increases in abdominal circumference induced by diaphragmatic contractions (natural or "active" breathing) or by positive pressure lung inflation (machine-assisted or "passive" breathing). In-house developed software modulated the flashing of the body/object outline according to respiratory movements, the highest intensity corresponding to the end of inspiration. The program produced the flashing surrounding the animated scene either synchronously or asynchronously with respect to the online detected inspiratory effort of each subject. In

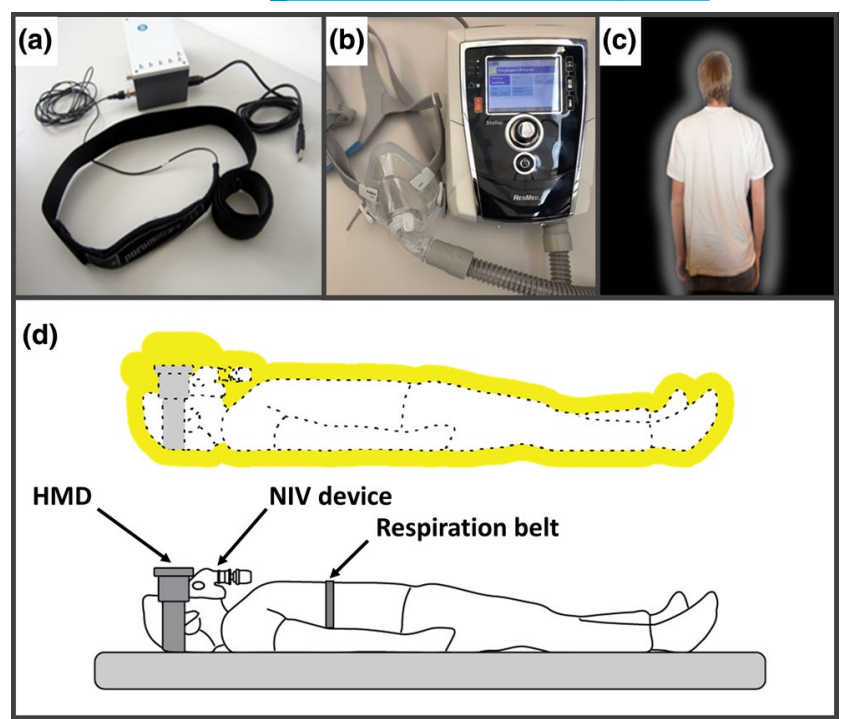

F IG URE 1 Setup and equipment for the experiment. The subjects were wearing a linear transducer mounted on respiration belt (a), a non-invasive mechanical ventilation (NIV) device (b). Participants were shown their own back illuminated synchronously (or asynchronously) with respect to their respiratory movements (c). Participants were wearing a Head-Mounted Display (HMD) and were in a supine position (d)

the synchronous condition, the body silhouette was flashing in synchrony with participant's on-going breathing. The asynchronous condition was created by replaying a prerecorded breathing pattern (out of phase with the breathing of the subject) and by adjusting in real time the replay speed to guarantee that the frequency of the signal was never the same as the actual breathing frequency of the subject (either $80 \%$ or $120 \%$ of the measured breathing frequency (Adler et al., 2014). Even if the participants were trying to catch up with the flashing consciously or unconsciously, this ensured that the flashing outline actually remained "out of phase" with the breathing frequency during the whole experimental condition.

In line with the study objective, the visuo-respiratory manipulations were performed during either "active breathing" or during "passive breathing," in random order. To this end, the participants were connected through a face mask to a NIV device (VPAP S9, Resmed, North Ryde, Australia). An experienced respiratory physician (DA) was in charge of adjusting the machine settings. In the "active breathing" mode, the respiratory backup rate (namely the number of breaths per minute that the machine delivers irrespective of the subject's breathing activity) was set to zero: all the breaths were initiated by the participants. In the "passive breathing" mode, the respiratory backup rate was progressively increased starting from the subjects' spontaneous breathing rate until breathing was "captured" and the subjects stopped triggering the machine ( $\mathrm{S} / \mathrm{T}$ mode). The objective was to produce more than 
$80 \%$ of machine-delivered respiratory cycles and less than $20 \%$ of cycles triggered by subjects' inspiratory efforts.

The percentage of subject initiated breaths was calculated for each passive breathing block, and a given block was excluded from analysis if this percentage was greater than $40 \%$. Other ventilator settings were kept constant across tested conditions and subjects (Expiratory Positive Airway Pressure: 3 cmH20; Inspiratory Positive Airway Pressure 9 cmH20; for details on the active/passive breathing manipulation see Section 2 of the Supporting Information).

Participants were not told about the relationship of the visual flashing with their respiration, and were not informed about the synchronous/asynchronous manipulations, prior to the study. Across the different experimental conditions, the ventilator mode allowed spontaneous breathing at every moment during the experiment, should this have been necessary.

\section{3 | Experimental procedure}

Participants were first welcomed to the experimental room and briefed about the experiment (e.g., the stimuli that they were going to see, the tasks that they would be asked to perform), before signing the consent form. The experiment was preceded by a short habituation session for participants to adapt to breathing through the NIV device, and to individualize the back-up rate for the passive blocks. Participants were instructed on how to use the mask and the NIV device, and they were asked to breathe through it for about five minutes. During this time, participants were comfortably lying on a mattress posed on the experimental table, $75 \mathrm{~cm}$ away from the ground. In order to set the S/T mode for each participant, we recorded his or her average respiration rate for $2 \mathrm{~min}$. The back-up rate of the NIV device was then increased progressively to $20 \%$ over the average subject's own respiratory rate. Subsequently, participants were asked to test the respiration through the NIV device by using this new back-up rate, which would be used in the experiment during the passive breathing condition.

Participants were then equipped with the HMD and installed in the supine position on the experimental table. Before the beginning of the experiment, participants performed a two-minute baseline session, both in active and passive mechanical ventilation mode, where they were asked to look at a black screen (through the HMD) and relax. The order of active and passive baseline blocks was counterbalanced between participants. Participants then underwent a 2-min FBI session either in the synchronous or asynchronous visuo-respiratory condition and either during active or passive mechanical ventilation mode $(2 \times 2$ factorial design). At the end of each experimental block, participants performed three trials of the Mental Ball Drop tasks (see below), and then, completed the FBI questionnaire. Each condition was repeated twice, presented in randomized order, for a total of eight experimental blocks.

\subsection{1 | FBI questionnaire}

In order to obtain subjective measurements of participants' feelings related to different aspects of BSC during the experiment, participants were presented with a modified version of the original FBI questionnaire at the end of each block, as in our previous studies (Allard et al., 2017; Aspell et al., 2013; Ionta et al., 2011; Lenggenhager et al., 2007; Pozeg, Galli,
TA B L E 1 Full-body illusion questionnaire: List of domains and items that participants had to rate according to a 7-point Likert scale (from $-3=$ totally disagree to $+3=$ totally agree)

\begin{tabular}{|c|c|c|}
\hline & Items & Domain \\
\hline Q1 & $\begin{array}{l}\text { It seemed as if I was feeling my respiration in } \\
\text { the virtual body }\end{array}$ & Location of breathing \\
\hline Q2 & It seemed as if the flashing was my respiration & Breathing awareness \\
\hline Q3 & $\begin{array}{l}\text { It seemed as if the virtual body was using my } \\
\text { lungs to breathe }\end{array}$ & Breathing agency \\
\hline Q4 & $\begin{array}{l}\text { I felt as if the virtual body was breathing with } \\
\text { me }\end{array}$ & Breathing agency \\
\hline Q5 & I felt as if the virtual body was my body & $\begin{array}{l}\text { Self-identification with the } \\
\text { virtual body }\end{array}$ \\
\hline Q6 & $\begin{array}{l}\text { I felt as if my real body was drifting toward the } \\
\text { virtual body }\end{array}$ & $\begin{array}{l}\text { Self-location with the } \\
\text { virtual body }\end{array}$ \\
\hline Q7 & It seemed as if I had two bodies & Control \\
\hline Q8 & $\begin{array}{l}\text { It seemed as if the machine was controlling my } \\
\text { respiration }\end{array}$ & $\begin{array}{l}\text { Control regarding } \\
\text { mechanical ventilation } \\
\text { mode }\end{array}$ \\
\hline Q9 & I felt as I was totally in control of my respiration & $\begin{array}{l}\text { Control regarding } \\
\text { mechanical ventilation } \\
\text { mode }\end{array}$ \\
\hline
\end{tabular}


\& Blanke, 2015). The questionnaire consisted of nine items (See Table 1). For each of them, participants were asked to rate how much they agreed or disagreed with the presented item, referring to the sensations experienced during the visual stimulation. We applied a 7-point Likert scale: $(-3=$ totally disagree to $+3=$ totally agree).

\subsection{2 | Self-location}

In addition to these subjective measurements, we used the Mental Ball Drop (MBD) task to measure perceived selflocation (Adler et al., 2014; Allard et al., 2017; Ionta et al., 2011; Pfeiffer et al., 2013). Thus, in every experimental condition, participants were asked to imagine dropping a ball from their hand (at the level of their body lying supine) to the floor. They pressed a button with their index finger when they imagined dropping the ball from their hand, held the button pressed during the imagined time of ball dropping, and released the button at the moment they imagined the ball hit the floor. The duration of the button press (response time, RT) has been shown to be a sensitive marker of self-location above the floor (Ionta et al., 2011; Lenggenhager, Mouthon, \& Blanke, 2009; Pfeiffer et al., 2013). A longer RT indicates an elevation of self-location (with respect to the floor), and thereby, a mislocalization toward the virtual body as well with a change in self-location. Three repeated MBDs were performed for each condition. Before the start of the experiment, participants performed a training session with at least 20 trials. Moreover, six repeated MBDs were performed as a baseline of participants' performance in this task.

\subsection{3 | Physiological parameters}

Mean tidal volume (Vt) and respiratory rate (RR), as well as their variabilities (defined as the $S D$ from the mean), were recorded by the ventilator for each tested condition. Vt can be underestimated by some home ventilators software, but has a constant and acceptable bias for the device used in our experiment (Contal et al., 2012). Vt refers to the volume of air moved in and out of the lungs during each inspiratory-expiratory cycle. We failed to measure physiological parameters for four participants for technical reasons.

\section{4 | Statistical analysis}

Data were screened for missing data and outliers using Mahalanobis distance (Tabachnick \& Fidell, 2012). Normality, linearity, and homogeneity of variance were checked and none of such assumptions were violated.
For the FBI questionnaire, a mixed-effects model for repeated-measures ANOVA was conducted on the subjective rating means separately for each question, with the factors mechanical ventilation mode (active, passive) and visuo-respiratory synchronicity (synchronous, asynchronous) as within-subject factors. The model also included a Mode*Synchronicity interaction and allowed for random intercepts.

For Mental Ball Drop data, mean of baseline RT and mean of RT were computed, for each condition. Then, baseline RT means were subtracted from the RT means of each condition. Such RT differences were entered in a mixed-effects model for repeated-measures ANOVA, with the factors mechanical ventilation mode (active, passive) and synchronicity (synchronous, asynchronous) as within-subject factors. The model also included a Mode*Synchronicity interaction and allowed for random intercepts.

Respiration rate, and Tidal Volume, as well as their variability were averaged and entered in separate mixed-effects models for repeated-measures ANOVA with the factors mechanical ventilation mode (active, passive) and synchronicity (baseline, synchronous, asynchronous) as within-subject factors. An outlier has been identified using Mahalanobis distance (Tabachnick \& Fidell, 2012): an extreme value of respiration rate variability was observed due to a technical issue, for one participant. The subject was removed from the analyses of the physiological data, resulting in sample of $n=12$ (female: $N=6$; age: Mean $\pm S D=25 \pm 3.9$ years).

All frequentist statistics were made using R 3.6.0 ( $\mathrm{R}$ Development Core Team, 2008). $p$ values were used as the basis of decision making in respect of the compared hypotheses. Differences were considered significant when the probability $p$ of a type I error was below 0.05 As suggested by the American Psychology Association (Wilkinson, 1999), for each result, we reported unstandardized effect sizes (i.e., difference between the means, $M D$ ). A non-significant $p$ value is not enough to provide evidence toward the null hypothesis or toward the fact that the data are insensitive and that additional data are needed to conclude (Dienes, 2014; Quintana $\&$ Williams, 2018). Therefore, to facilitate the interpretation of our data, we ran separate Bayesian repeated-measure analyses of variance. Each analysis (with default scale fixed effects, default scale random effects) included three models: (a) a model including an effect of mechanical ventilation mode (active, passive), (b) a model including an effect of visuo-respiratory synchronicity (synchronous, asynchronous), (c) a model including main effects and their interaction. For each analysis, each model was compared to a null model (model only including subjects). For each model comparison, a Bayes factor $(B F)$ was computed. The $B F$ was then used to interpret our results when traditional statistics were inconclusive, in respect of the compared hypotheses regarding the effect of synchronicity (e.g., preference of the model including an effect 
of synchronicity over the null model) and the effect of mode (e.g., preference of the model including an effect of mode over the null model). A $B F$ below $1 / 3$ provides substantial evidence toward the null hypothesis (i.e., preference of the null model over the effect model; with $1 / 10<B F<1 / 3=$ moderate evidence; $B F<1 / 10=$ strong evidence), whereas a $\mathrm{BF}$ above 3 shows compelling evidence toward the alternative hypothesis (i.e., preference of the effect model over the null model; with $3<B F<10=$ moderate evidence; $B F>10=$ strong evidence). A $B F$ between 3 and 1/3 implies there is not enough evidence in either direction (Jeffreys, 1961; Lee \& Wagenmakers, 2014). All Bayesian analyses were run using JASP 0.9.1.0 (Wagenmakers et al., 2018).

\section{\begin{tabular}{l|l}
3 & RESULTS
\end{tabular}}

\section{1 | FBI questionnaire}

A separate mixed-effects model for repeated-measures ANOVA and Bayesian repeated-measures ANOVA were run for each item, in order to evaluate the effect of synchrony and mechanical ventilation mode. Full statistical results including Bayesian analyses are presented in Tables S1 and S2 in the Supporting Information Section 3.

Seeing the virtual body flashing in synchrony with their respiratory movements (synchronous condition) induced the participants to misperceive their breathing at the position of the virtual body (Q1). Such changes were absent in the asynchronous condition, showing a significant difference between the synchronous $(M \pm S D: 0.05 \pm 1.5)$ and the asynchronous condition $(-1.28 \pm 1.14)(F(1,48)=8.67, p<.01$, $M D=1.33, B F=10.12)$. Participants also perceived the flashing as more related to their respiration (breathing awareness; Q2) in the synchronous $(0.84 \pm 1.3)$, as compared to the asynchronous condition $(-1.37 \pm 1.38 ; F(1,48)=54.48, p<$ $.001, M D=2.21, B F>100)$. Participants' breathing agency was also modulated, depending on whether they received synchronous (Q3: $-0.45 \pm 1.28$; Q4: $0.05 \pm 1.36)$ or asynchronous stimulation $(\mathrm{Q} 3:-1.69 \pm 1.04$; $44:-1.46 \pm 1.2$; Q3: $F(1,48)=25.72, p<.001, M D=1.24 ; B F>100$; $\mathrm{Q} 4: F(1,48)=28.16, p<.001, M D=1.51, B F=10.15)$. Illusory self-identification (Q5) was numerically higher in the synchronous $(0.01 \pm 1.4)$ versus asynchronous condition $(-0.45 \pm 1.56 ; F(1,48)=5.32, p<.05), M D=0.46$, $B F=2.113)$. Effects of synchrony on ratings $(\mathrm{Q} 1-\mathrm{Q} 5)$ are graphically represented on Figure 2 . There was no other significant main effect or interaction (all $p>.1$ ). As expected, moderate evidence against the hypothesis of preferring the synchrony effect model over the null model was observed for the control items Q7 ("It seemed as if I had two bodies") and Q8 ("It seemed as if the machine was controlling my respiration"; Q7: $F(1,48)=0.30, p=.59, B F=0.277$, Q8:

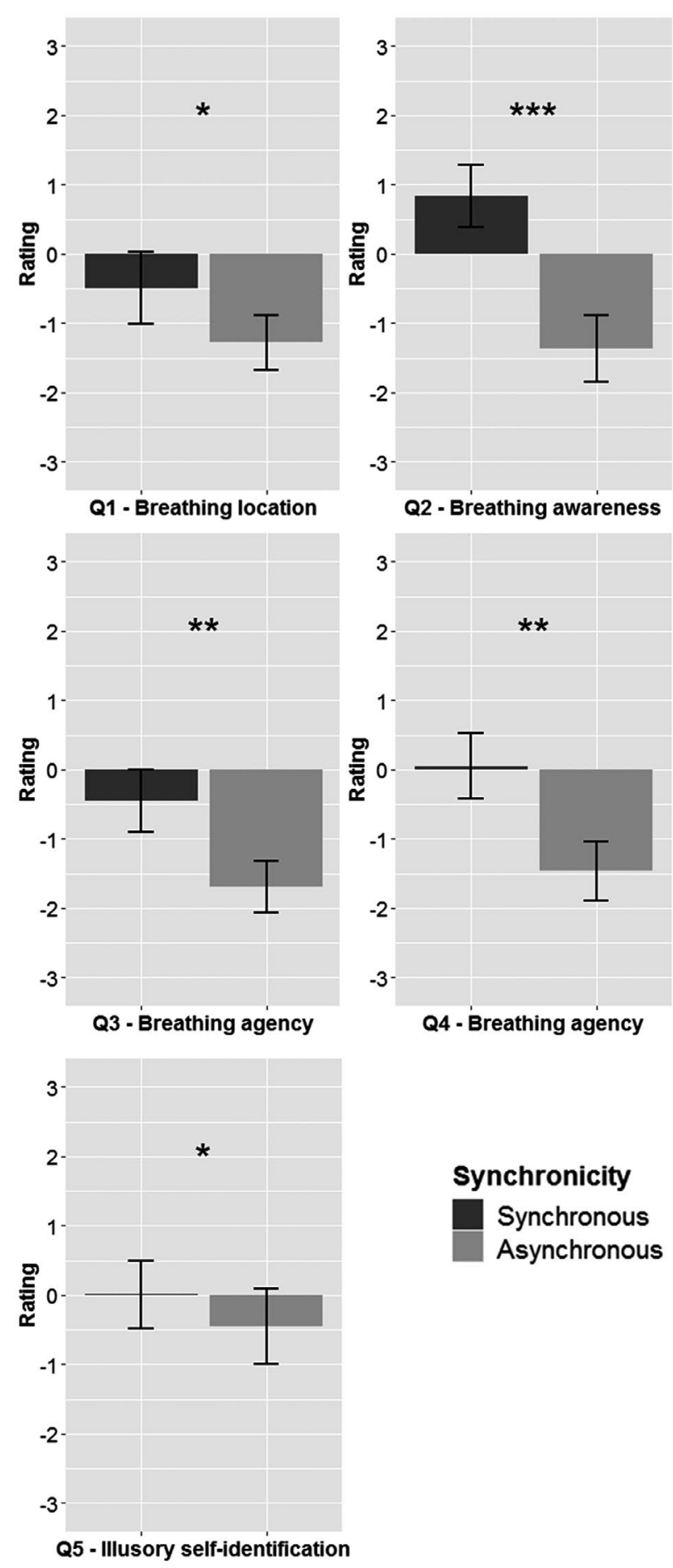

F I G URE 2 Full-body illusion questionnaire ratings. Main effect of synchrony on subjective ratings of items Q1-Q5, with error bars representing lower and upper Gaussian confidence limits ${ }^{*} p$ $<.05, * * p<.01, * * * p<.001$ ) (Q1 It seemed as if I was feeling my respiration in the virtual body; Q2 It seemed as if the flashing was my respiration; Q3 It seemed as if the virtual body was using my lungs to breathe; Q4 I felt as if the virtual body was breathing with me; Q5 I felt as if the virtual body was my body)

$F(1,48)=0.06, p=.81, B F=0.26)$. Absence of evidence in either direction (null model or synchronicity effect model) was observed for Q6 (Illusory self-location) and the control 
item related to breathing Q9 ("I felt as I was totally in control of my respiration"; Q6: $F(1,48)=2.67, p=.11, B F=0.768$, Q9: $F(1,48)=1.84, p=.18, B F=0.516)$.

Participants were aware of the active/passive breathing manipulation, as shown by the main effect of mechanical ventilation mode for Q8 $(F(1,48)=15.04, p<.001, M D=$ $-1.2, B F>100)$. Participants agreed more with the statement that the machine was controlling their respiration in the passive breathing condition $(1.25 \pm 1.25)$, as compared to the Active breathing one $(0.05 \pm 1.73, p<.01)$. As expected, control statement regarding breathing (Q9) was also modulated by the active/passive breathing manipulation: ratings were greater during active condition $(0.48 \pm 1.67)$ compared to ratings during passive condition $(-0.48 \pm 1.66$; $F(1,48)=7.41, p<.01, M D=0.96, B F=5.81)$. Effects of mode on ratings (Q8-Q9) are graphically represented on Figure 3. There was no other main effect or interaction (all $p>$.1). A moderate evidence against the hypothesis of preferring the mode effect model over the null model was observed for self-location (Q1), breathing awareness (Q2), breathing agency (Q3-Q4), and illusory self-location (Q6; Q1: $F(1,48)$ $=0.00, p=.95, B F=0.241 ; \mathrm{Q} 2: F(1,48)=0.99, p=.33$, $B F=0.315 ; \mathrm{Q} 3: F(1,48)=0.00, p=.96, B F=0.248 ; \mathrm{Q} 4:$ $F(1,48)=2.41, p=.63, B F=0.265$; Q6: $F(1,48)=0.05, p$ $=.83, B F=0.249)$. Absence of evidence in either direction (null model or mode effect model) was observed for illusory self-identification (Q5) and for the control statement (Q7) $(\mathrm{Q} 5: F(1,48)=2.05, p=.16, B F=0.547 ; \mathrm{Q} 7: F(1,48)=$ $1.65, p=.21, B F=0.517)$.

To sum up, synchrony of visuo-respiratory stimulation was modulating self-location, breathing awareness, breathing agency, and illusory self-identification. Despite the fact that participants agreed more that the machine was controlling their breathing in the passive condition compared to the active one, our data do not support a main effect of ventilation mode (active vs. passive) on subjective measure of BSC, including breathing agency. No interaction was significant.

\section{2 | Self-location}

Changes in subjective breathing sensations were supported by a drift in self-location (i.e., MBD; Figure 4). Compared to baseline, RTs were significantly longer after synchronous (Mean $\pm S D,-20.51 \mathrm{~ms} \pm 370.56 \mathrm{~ms}$ ) than after asynchronous respiratory visual stimulation $(-89.85 \mathrm{~ms} \pm 343.38 \mathrm{~ms}$; +69 ms; $F(1,48)=4.96, p<.05, M D=69.34 \mathrm{~ms}, B F=1.9$ ), showing that our participants perceived themselves to be closer to the virtual body in the synchronous than the asynchronous condition. There was no other main effect or interaction (all $p>.30$ ). A moderate evidence against the hypothesis of preferring the mode effect model over the null model was observed for RT differences $(F(1,48)=0.08, p$ $=.78, B F=0.269$ ). Full traditional and Bayesian analyses are presented in Tables S3 and S4 in Supporting Information Section 3.

To sum up, synchrony of visuo-respiratory stimulations, but not ventilation mode (active vs. passive), modulates the behavioral measure of self-location. Our data do not seem to support a main effect of mechanical ventilation mode on such measures. No interaction was significant.

\section{3 | Physiological parameters}

By design, respiration rate was significantly higher (passive: $M=20.71 \pm 3.42$; Active: $M=16.55 \pm 4.19 ; F(1,33)=$ $109.07, p<.001, M D=-4.16)$, and its variability was lower (passive: $M=1.3 \pm 1.03$; active: $M=2.44 \pm 1.03 ; F(1,33)$ $=33.69, p<.001, M D=1.14$ ), during passive compared to active breathing. Tidal volume was higher during active
FI G URE 3 Full-body illusion questionnaire ratings (breathing control). Main effect of mechanical ventilation mode on subjective ratings of items Q8 (It seemed as if the machine was controlling my respiration) and Q9 (I felt as I was totally in control of my respiration), with error bars representing lower and upper Gaussian confidence limits $(* * p<.01)$
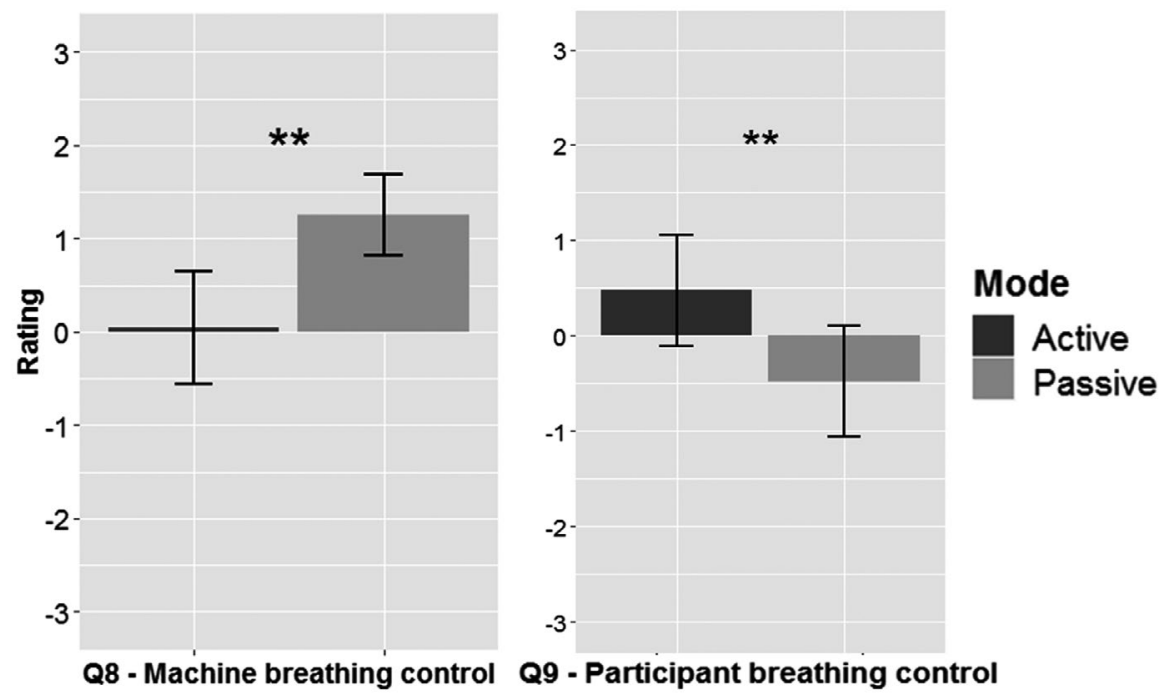


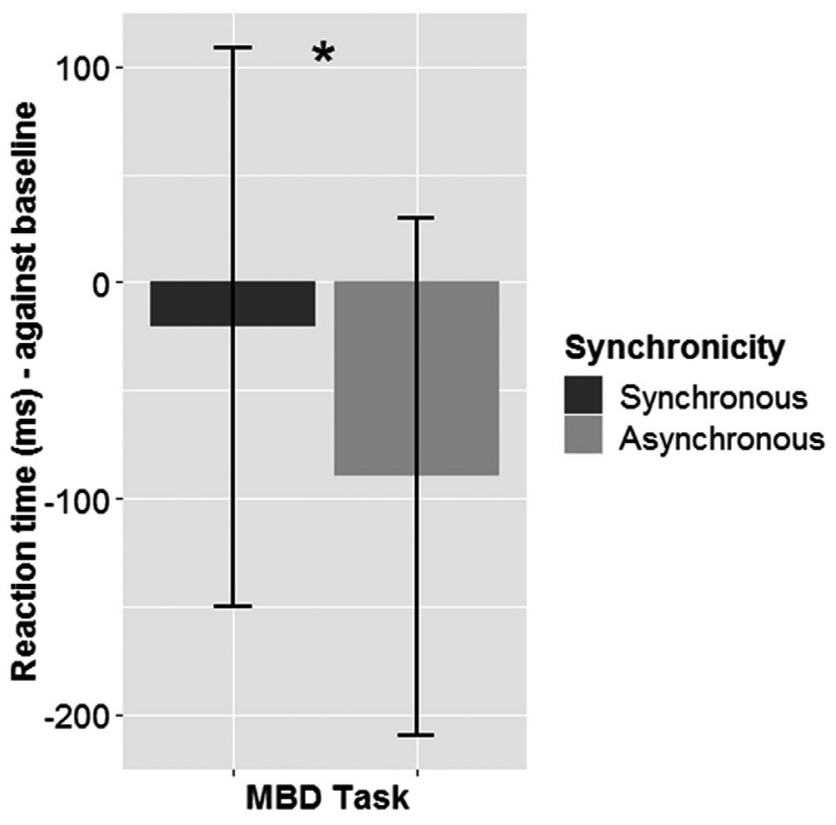

F I G U RE 4 Self-location (drift). Mental Ball Dropping (MBD) Task: main effect of synchronicity on reaction time in ms (against baseline), with error bars representing lower and upper Gaussian confidence limits $(* p<.05)$

than passive breathing (passive: $M=0.53 \pm 1.45$; active: $M=0.62 \pm 0.14 ; F(1,33)=17.72, p<.001, M D=0.09)$.

We observed an effect of synchrony for tidal volume variability: tidal volume variability was greater during asynchronous stimulations compared to synchronous stimulations (asynchronous: $M=0.1 \pm 0.04$; synchronous $M=0.08 \pm 0.04 ; F(1,33)=4.15, p<.05, M D=-0.02$, Figure 5). Moderate evidence against the hypothesis of preferring the synchrony effect model over the null model was observed for respiration rate $(B F=0.281)$ and tidal volume $(B F=0.276)$. Absence of evidence in either direction (null model or synchronicity effect model) was observed for respiration rate variability $(B F=0.346)$.

Effects of mode and synchrony on ventilatory variables, as well as their means and SDs are described in Table 2. Full Bayesian analyses are presented in Table S5 in Supporting Information Section 3.

To sum up, whereas by design passive breathing modulated several ventilatory variables, tidal volume variability was modulated by the synchrony of visuo-respiratory stimulations. No interaction was significant.

\section{4 | DISCUSSION}

The aim of the present study was to determine whether or not respiratory motor commands contribute to BSC. Three key results were observed. First, our results replicate findings from previous work using the visuo-respiratory FBI to evaluate the

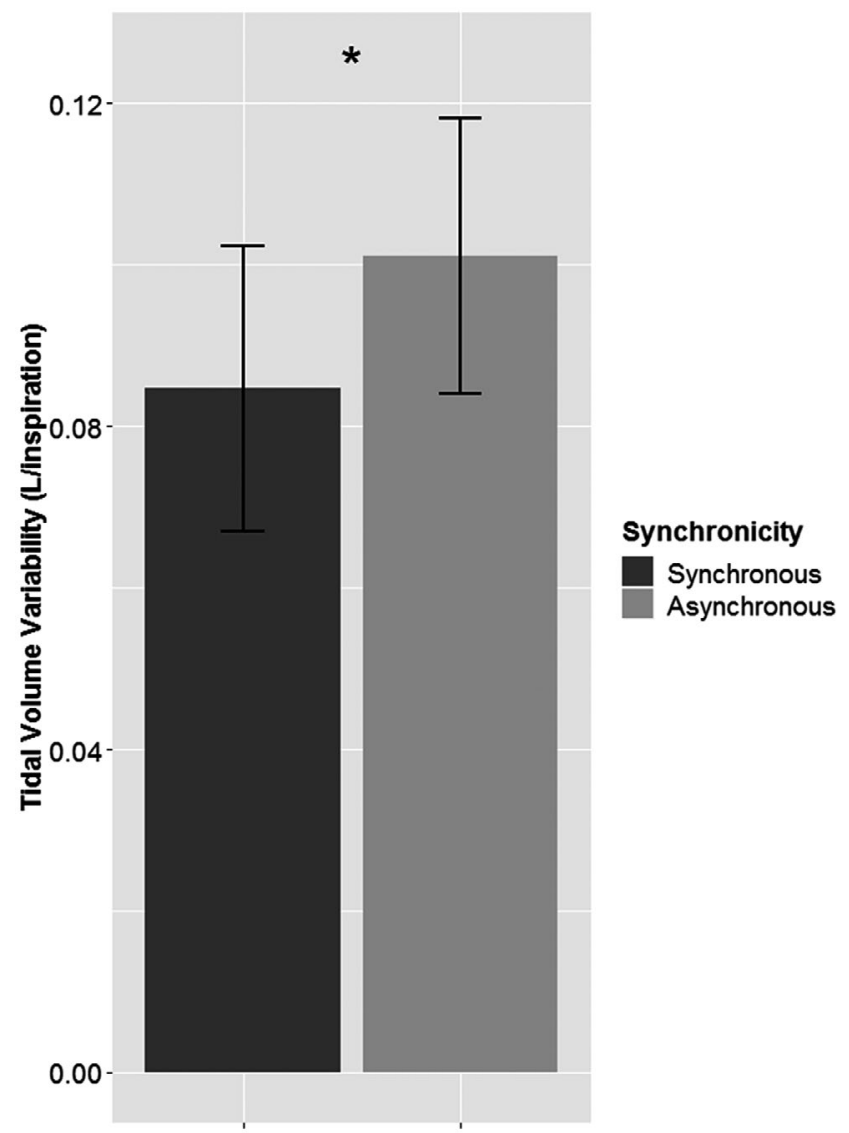

F IG URE 5 Physiology. Main effect of synchronicity on tidal volume variability (L/breath), with error bars representing lower and upper Gaussian confidence limits $\left({ }^{*} p<.05\right)$

contribution of breathing to BSC (Adler et al., 2014; Allard et al., 2017): synchrony of visuo-respiratory stimulations is associated with greater self-location toward the virtual body and greater breathing agency. These subjective effects were corroborated by a similar effect on self-location objectified with the MBD task; prolonged MDB times, indicating a behavioral change in self-location toward the virtual body in the synchronous as compared to the asynchronous condition, were observed. Taken together, these findings suggests that the synchrony of visuo-respiratory stimulations reliably induces an altered state of BSC characterized by changes in breathing agency and self-location (Adler et al., 2014; Allard et al., 2017). In line with Allard and colleagues, we observed that synchronous stimulation increased illusory self-identification toward the virtual avatar. This is further supported by a recent study showing that ownership over a 3D breathing avatar is greater if the avatar is breathing in synchrony with the participant compared to a condition when the avatar is breathing in antiphase (Monti et al., 2020).

Second, previous studies as well as the current study showed that respiratory visual synchronization strongly and specifically impacts breathing agency (Adler et al., 2014; Allard et al., 2017). Yet, contrary to our hypothesis, 
T A B L E 2 Mean, $S D$ and results of separate mixed-effects model for repeated-measures ANOVA run for respiration rate, respiration rate variability, tidal volume, and tidal volume variability, evaluating the effect of synchronicity and mode ( $p$ values $<.05$ are represented in bold)

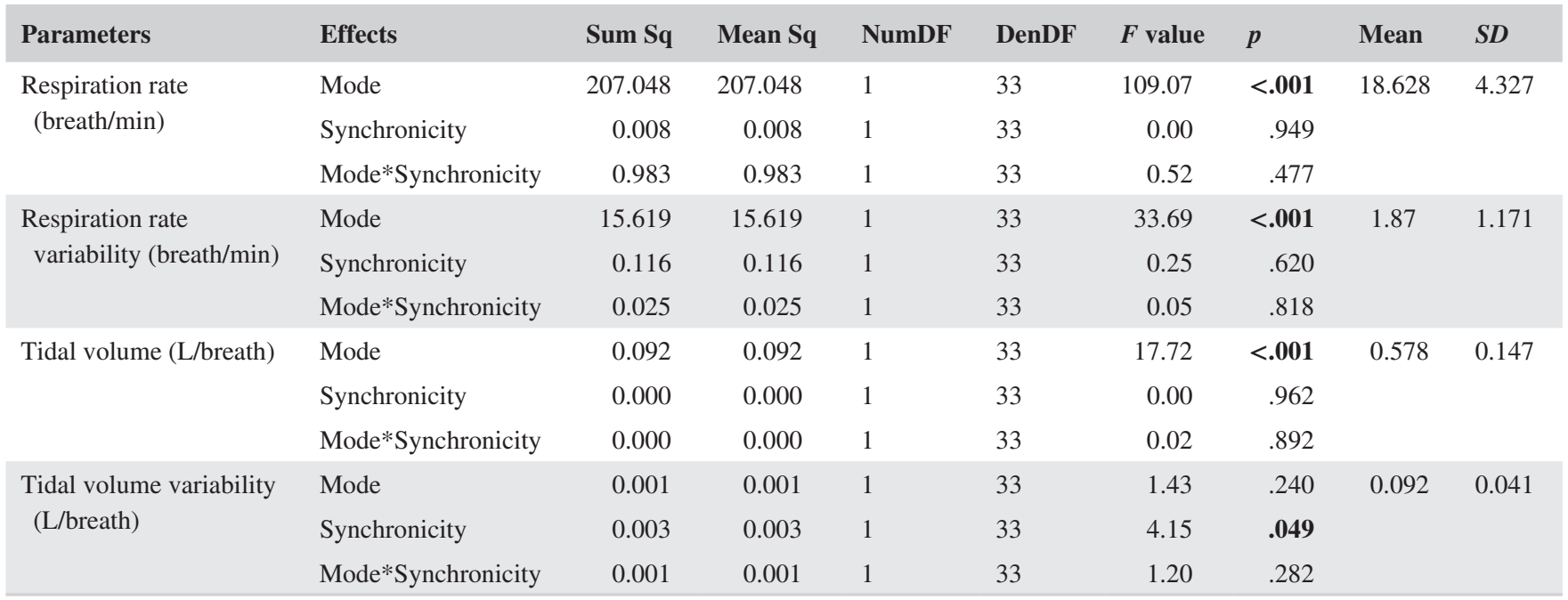

mechanical ventilation mode (i.e., active vs. passive) did not affect BSC in the current study. The sense of agency refers to the experience of controlling one's own actions, and, through them, events in the outside world (Haggard \& Chambon, 2012). This sense of agency has been proposed to emerge from both the initiation of an action and a match between the predicted sensory feedback (which is inferred from the efference copy of the motor command) and the actual sensory feedback of the action (Blakemore et al., 2000; Blakemore et al., 2000; Daprati \& Sirigu, 2002; Haggard, 2017). Kalckert and Ehrsson (2012) investigated the role of the sense of agency in modulating BSC by using a modified version of the rubber hand illusion (RHI) paradigm. In that study, the authors induced the RHI using synchronous and asynchronous visuo-motor stimulations over active (i.e., efference copy) and passive finger movements (i.e., no efference copy). The passivity of the movement created a break in agency, suggesting that the motor command initiation and the efference copy generation are essential in the genesis of the sense of agency (Haggard, 2017; Kalckert \& Ehrsson, 2012; for related studies on agency and hand ownership using TMS and VR see also Bassolino et al., 2018; Franza et al., 2019).

In the present study, we used a NIV device to control for breathing initiation. By capturing the participants' spontaneous breathing rhythm and by administering machine-assisted breathing at a faster rate, we decreased the likeliness of naturally initiated breaths. As a result, while in the active breathing conditions, a motor command, and an efference copy were produced, this was not (or much less) the case during the passive breathing conditions. Our data do not, for the most part, support a main effect of mechanical ventilation mode on the subjective or objective measures of BSC, unlike the results from previous work on BSC related to limb representations (Kalckert \& Ehrsson, 2012). We argue that this is most likely due to methodological differences between the manipulation of visuo-respiratory signals in the current experiment, and the visuo-motor manipulations of hand or full-body actions in related agency research for hand and full-body actions (Adler et al., 2014; Allard et al., 2017; Kalckert \& Ehrsson, 2012). Thus, NIV may still allow participants to initiate breaths to some extent (associated with efferent motor commands), which were absent or more easily controlled in the study by Kalckert \& Ehrsson when testing upper limb representation. Several differences with respect to previous experiments and the present breathing-related manipulations may account for this, in addition to motor commands and efference copy-related signals, between active and passive conditions. Thus, minute ventilation was higher during passive than during active breathing $(+0.7 \mathrm{~L}$ on average) and this could have slightly lowered blood carbon dioxide and provoked an accompanying reduction in neural drive to breathe. The neural drive to breathe was also probably blunted by the application of positive pressure breathing, independently of any effect on gas exchange, as previously shown when applying comparable interventions to healthy subjects (Fauroux et al., 1998; Sharshar et al., 2004). Our breathing manipulation was validated by participants agreeing more with the statement that the ventilator was controlling their respiration in the passive breathing condition compared to the active breathing one. Nevertheless, in the present experiment, the synchrony effect was observed in both passive and active conditions, suggesting that the visuo-respiratory $\mathrm{FBI}$ is rather driven by the respiratory-related afferent traffic to the brain (exteroceptive, proprioceptive, and interoceptive) rather than by the efferent motor signals, as suggested by some recent work using the RHI (Isayama et al., 2019) and compatible with proposals that afferent multisensory signals are sufficient to induce changes in BSC. Further studies should try to determine the contribution of different afferent pathways by more strongly and more selectively manipulating the different channels. 
A third finding was a synchrony-dependent change in tidal volume variability that is a marker of a healthy breathing system (Fiamma et al., 2007; Mangin et al., 2008; Tobin et al., 1988). Reduced tidal volume variability has been associated with dyspnea and respiratory discomfort sensations in patients (Brack, Jubran, \& Tobin, 2002; Parshall et al., 2012). In the present study, tidal volume variability was greater in the asynchronous visuo-respiratory stimulation condition compared to the synchronous condition and this effect was absent for tidal volume. This could be put in the perspective of a previous experiment investigating the visuo-respiratory FBI under normal and loaded breathing (i.e., inducing dyspnea), where we observed a reduction of breathing discomfort induced by an inspiratory mechanical load during the asynchronous visuo-respiratory stimulation condition (again compared to the synchronous condition) (Allard et al., 2017). Accordingly, we postulate that the reduction in the aversive dimension of dyspnea during asynchronous visuo-respiratory stimulation may have been associated with the increased tidal volume variability in the present study. Increased tidal volume enrichens the afferent traffic to the brain and may contribute to correcting the dyspnea-generating sensorimotor imbalance, but this mechanism should be explicitly tested in further work. Another potential explanation for changes in tidal volume variability could come from the fact that respiration is a cyclic, highly automated, continuous, and not immediately goal-directed action, somewhat similar to gait. Kannape \& Blanke showed that participants walking while receiving (synchronous or delayed) visual gait feedback, systematically and unconsciously adjusted their stride time in order to synchronize their gait to that of the visual feedback, in function of the delay (see Kannape \& Blanke, 2013). Thus, we speculate that our participants may have tried to unconsciously adjust their breathing to the asynchronous visuo-respiratory feedback leading to increase variability of the tidal volume. As the asynchronous condition was alternating between either $80 \%$ or $120 \%$ of the participant's breathing frequency, this effect could have been canceled out in the mean tidal volume but preserved in its variability. Although we did not find an adjustment effect on respiration rate, a recent study found that participants who embodied a 3D-avatar were unconsciously adjusting their respiration rate to the respiration rate of the avatar (Czub \& Kowal, 2019). Further studies should explore the relationship between unconscious breathing synchronization and breathing agency. Systematically inducing breathing adaptation using virtual reality (VR), without breaking the sense of agency, could have a meaningful clinical impact and potentially inform the development of dyspnea-relieving tools.

The results of this study should be considered in light of several constraints. First, to maximize experimental standardization, parameters of the ventilator (e.g., Expiratory and Inspiratory Positive Airway Pressure) were kept constant across all participants. Locking these settings across subjects might have led to individually different sensory experiences. Future studies using similar set-up should measure degree of breathlessness, discomfort, or ease for each participant or should tailor the settings in a way to meet respiratory comfort. In the same frame, the active and the passive condition could have corresponded to different levels of $\mathrm{PaCO}_{2}$. Future work may also monitor these differences by non-invasively measuring expired $\mathrm{CO}_{2}$, using infrared absorption spectroscopy (Huttmann, Windisch, \& Storre, 2014). Also, a hallmark of breathing is the complementarity between its voluntary and spontaneous breathing mechanisms. Given the use of a ventilator and participants' awareness regarding the breathing manipulation, we postulate that in the active breathing condition (as well as to some degree in the passive one), cortical influences on respiration were still present (Herrero, Khuvis, Yeagle, Cerf, \& Mehta, 2018). The coupling of our experimental set-up with neuroimaging (e.g., fMRI or iEEG) would also be important to clarify the involved BSC structures (Blanke, 2012), the involved respiratory structures (Herrero et al., 2018), and, importantly, which regions mediate between both systems at the cortical and subcortical level. Finally, future work should also account for trait differences in phenomenological control (see Lush et al., preprint; Palfi, Moga, Lush, Scott, \& Dienes, preprint).

To conclude, this study experimentally examines the contribution of breathing motor command on BSC. We replicated and extended previous FBI findings showing that visuo-respiratory stimulation affects both subjective and objective measures of BSC, independent from the additional sensorimotor signals in the active condition, at least as tested in the present experiment. Moreover, visuo-respiratory effects were particularly important for breathing agency. Finally, variability of respiratory physiological parameters, a marker of a healthy respiratory system, was influenced by visuo-respiratory feedback and may relate to the dyspnea alleviating effects of asynchronous visuo-respiratory stimulation observed previously. Further investigations of BSC and respiratory physiology and perception might inform the development of respiratory diagnostic and therapeutic tools using VR in patients suffering from acute dyspnea, chronic dyspnea, or hyperventilation syndrome.

\section{ORCID}

Sophie Betka (D) https://orcid.org/0000-0001-9548-4391

\section{REFERENCES}

Adler, D., Herbelin, B., Similowski, T., \& Blanke, O. (2014). Breathing and sense of self: Visuo-respiratory conflicts alter body self-consciousness. Respiratory Physiology \& Neurobiology, 203, 68-74. https://doi.org/10.1016/j.resp.2014.08.003 
Adler, D., \& Janssens, J.-P. (2019). The Pathophysiology of respiratory failure: Control of breathing, respiratory load, and muscle capacity. Respiration; International Review of Thoracic Diseases, 97(2), 93-104. https://doi.org/10.1159/000494063

Allard, E., Canzoneri, E., Adler, D., Morélot-Panzini, C., Bello-Ruiz, J., Herbelin, B., ... Similowski, T. (2017). Interferences between breathing, experimental dyspnoea and bodily self-consciousness. Scientific Reports, 7, 9990. https://doi.org/10.1038/s41598-01711045-y

Aspell, J. E., Heydrich, L., Marillier, G., Lavanchy, T., Herbelin, B., \& Blanke, O. (2013). Turning body and self inside out: Visualized heartbeats alter bodily self-consciousness and tactile perception. Psychological Science, 24(12), 2445-2453. https://doi. org/10.1177/0956797613498395

Bassolino, M., Franza, M., Bello Ruiz, J., Pinardi, M., Schmidlin, T., Stephan, M. A., ... Blanke, O. (2018). Non-invasive brain stimulation of motor cortex induces embodiment when integrated with virtual reality feedback. The European Journal of Neuroscience, 47(7), 790-799. https://doi.org/10.1111/ejn.13871

Blakemore, S. J., Wolpert, D., \& Frith, C. (2000). Why can't you tickle yourself? NeuroReport, 11(11), R11-R16.

Blanke, O. (2012). Multisensory brain mechanisms of bodily self-consciousness. Nature Reviews Neuroscience, 13(8), 556-571. https:// doi.org/10.1038/nrn3292

Blanke, O., Slater, M., \& Serino, A. (2015). Behavioral, neural, and computational principles of bodily self-consciousness. Neuron, 88(1), 145-166. https://doi.org/10.1016/j.neuron.2015.09.029

Brack, T., Jubran, A., \& Tobin, M. J. (2002). Dyspnea and decreased variability of breathing in patients with restrictive lung disease. American Journal of Respiratory and Critical Care Medicine, 165(9), 1260-1264. https://doi.org/10.1164/rccm.2201018

Buchanan, G. F., \& Richerson, G. B. (2009). Role of chemoreceptors in mediating dyspnea. Respiratory Physiology \& Neurobiology, 167(1), 9-19. https://doi.org/10.1016/j.resp.2008.12.002

Burki, N. K., \& Lee, L.-Y. (2010). Mechanisms of dyspnea. Chest, 138(5), 1196-1201. https://doi.org/10.1378/chest.10-0534

Colebatch, J. G., Adams, L., Murphy, K., Martin, A. J., Lammertsma, A. A., Tochon-Danguy, H. J., ... Guz, A. (1991). Regional cerebral blood flow during volitional breathing in man. The Journal of Physiology, 443, 91-103.

Contal, O., Vignaux, L., Combescure, C., Pepin, J.-L., Jolliet, P., \& Janssens, J.-P. (2012). Monitoring of noninvasive ventilation by built-in software of home bilevel ventilators: A bench study. Chest, 141(2), 469-476. https://doi.org/10.1378/chest.11-0485

Czub, M., \& Kowal, M. (2019). Respiration entrainment in virtual reality by using a breathing avatar. Cyberpsychology, Behavior, and Social Networking, 22(7), 494-499. https://doi.org/10.1089/ cyber.2018.0700

Daprati, E., \& Sirigu, A. (2002). Laterality effects on motor awareness. Neuropsychologia, 40(8), 1379-1386. https://doi.org/10.1016/ S0028-3932(01)00203-2

Davenport, P. W., \& Vovk, A. (2009). Cortical and subcortical central neural pathways in respiratory sensations. Respiratory Physiology \& Neurobiology, 167(1), 72-86. https://doi.org/10.1016/j. resp.2008.10.001

R Development Core Team. (2008). R: A language and environment for statistical computing. Consulté à l'adresse http://www.R-project.org

Dienes, Z. (2014). Using Bayes to get the most out of non-significant results. Frontiers in Psychology, 5, 781. https://doi.org/10.3389/ fpsyg.2014.00781
Ehrsson, H. H. (2007). The experimental induction of out-of-body experiences. Science (New York, N.Y.), 317(5841), 1048-1048. https:// doi.org/10.1126/science.1142175

Ehrsson, H. H. (2012). The concept of body ownership and its relation to multisensory integration. In G. A. Calvert, C. Spence, \& B. E. Stein (Eds.), The new handbook of multisensory processes (pp. 775-792). Boston, MA: MIT.

Fauroux, B., Isabey, D., Desmarais, G., Brochard, L., Harf, A., \& Lofaso, F. (1998). Nonchemical influence of inspiratory pressure support on inspiratory activity in humans. Journal of Applied Physiology (Bethesda, Md.: 1985), 85(6), 2169-2175. https://doi.org/10.1152/ jappl.1998.85.6.2169

Fiamma, M.-N., Straus, C., Thibault, S., Wysocki, M., Baconnier, P., \& Similowski, T. (2007). Effects of hypercapnia and hypocapnia on ventilatory variability and the chaotic dynamics of ventilatory flow in humans. American Journal of Physiology-Regulatory, Integrative and Comparative Physiology, 292(5), R1985-R1993. https://doi. org/10.1152/ajpregu.00792.2006

Foerster, O. (1936). Motorische Felder und Bahnen.In O. Bumke \& O. Foerster (Eds.), Handbuch der Neurologie (pp. 50-51). Berlin, Germany: Springer.

Franza, M., Sorrentino, G., Vissani, M., Serino, A., Blanke, O., \& Bassolino, M. (2019). Hand perceptions induced by single pulse transcranial magnetic stimulation over the primary motor cortex. Brain Stimulation, 12(3), 693-701. https://doi.org/10.1016/j. brs.2018.12.972

Haggard, P. (2017). Sense of agency in the human brain. Nature Reviews Neuroscience, 18(4), 196-207. https://doi.org/10.1038/nrn.2017.14

Haggard, P., \& Chambon, V. (2012). Sense of agency. Current Biology, 22(10), R390-R392. https://doi.org/10.1016/j.cub.2012.02.040

Haouzi, P., \& Bell, H. J. (2009). Control of breathing and volitional respiratory rhythm in humans. Journal of Applied Physiology (Bethesda, Md.: 1985), 106(3), 904-910. https://doi.org/10.1152/ japplphysiol.90675.2008

Haouzi, P., Chenuel, B., \& Barroche, G. (2006). Interactions between volitional and automatic breathing during respiratory apraxia. Respiratory Physiology \& Neurobiology, 152(2), 169-175. https:// doi.org/10.1016/j.resp.2005.08.004

Herrero, J. L., Khuvis, S., Yeagle, E., Cerf, M., \& Mehta, A. D. (2018). Breathing above the brain stem: Volitional control and attentional modulation in humans. Journal of Neurophysiology, 119(1), 145159. https://doi.org/10.1152/jn.00551.2017

Huttmann, S. E., Windisch, W., \& Storre, J. H. (2014). Techniques for the measurement and monitoring of carbon dioxide in the blood. Annals of the American Thoracic Society, 11(4), 645-652. https:// doi.org/10.1513/AnnalsATS.201311-387FR

Ionta, S., Heydrich, L., Lenggenhager, B., Mouthon, M., Fornari, E., Chapuis, D., ... Blanke, O. (2011). Multisensory mechanisms in temporo-parietal cortex support self-location and first-person perspective. Neuron, 70(2), 363-374. https://doi.org/10.1016/j. neuron.2011.03.009

Isayama, R., Vesia, M., Jegatheeswaran, G., Elahi, B., Gunraj, C. A., Cardinali, L., ... Chen, R. (2019). Rubber hand illusion modulates the influences of somatosensory and parietal inputs to the motor cortex. Journal of Neurophysiology, 121(2), 563-573. https://doi. org/10.1152/jn.00345.2018

Jeffreys, H. (1961). Theory of probability (3rd ed.). Oxford, UK: Oxford University Press.

Kalckert, A., \& Ehrsson, H. H. (2012). Moving a rubber hand that feels like your own: A dissociation of ownership and agency. 
Frontiers in Human Neuroscience, 6, 40. https://doi.org/10.3389/ fnhum.2012.00040

Kannape, O. A., \& Blanke, O. (2013). Self in motion: Sensorimotor and cognitive mechanisms in gait agency. Journal of Neurophysiology, 110(8), 1837-1847. https://doi.org/10.1152/jn.01042.2012

Killian, K. J., Gandevia, S. C., Summers, E., \& Campbell, E. J. (1984). Effect of increased lung volume on perception of breathlessness, effort, and tension. Journal of Applied Physiology, 57(3), 686-691. https://doi.org/10.1152/jappl.1984.57.3.686

Lee, M., \& Wagenmakers, E.-J. (2014). Bayesian cognitive modeling: A practical course. Cambridge: Cambridge University Press.

Lenggenhager, B., Mouthon, M., \& Blanke, O. (2009). Spatial aspects of bodily self-consciousness. Consciousness and Cognition, 18(1), 110-117. https://doi.org/10.1016/j.concog.2008.11.003

Lenggenhager, B., Tadi, T., Metzinger, T., \& Blanke, O. (2007). Video ergo sum: Manipulating bodily self-consciousness. Science (New York, N.Y.), 317(5841), 1096-1099. https://doi.org/10.1126/scien ce. 1143439

Lush, P., Botan, V., Scott, R. B., Seth, A. K., Ward, J., \& Dienes, Z. (preprint). Phenomenological control: Response to imaginative suggestion predicts measures of mirror touch synaesthesia, vicarious pain and the rubber hand illusion. https://doi.org/10.31234/ osf.io/82jav

Mangin, L., Fiamma, M.-N., Straus, C., Derenne, J.-P., Zelter, M., Clerici, C., \& Similowski, T. (2008). Source of human ventilatory chaos: Lessons from switching controlled mechanical ventilation to inspiratory pressure support in critically ill patients. Respiratory Physiology \& Neurobiology, 161(2), 189-196. https:// doi.org/10.1016/j.resp.2008.02.006

Monti, A., Porciello, G., Tieri, G., \& Aglioti, S. M. (2020). The "embreathment" illusion highlights the role of breathing in corporeal awareness. Journal of Neurophysiology, 123(1), 420-427. https:// doi.org/10.1152/jn.00617.2019

Palfi, B., Moga, G., Lush, P., Scott, R. B., \& Dienes, Z. (preprint). Can hypnotic suggestibility be measured online?

Park, H.-D., Bernasconi, F., Bello-Ruiz, J., Pfeiffer, C., Salomon, R., \& Blanke, O. (2016). Transient modulations of neural responses to heartbeats covary with bodily self-consciousness. Journal of Neuroscience, 36(32), 8453-8460. https://doi.org/10.1523/JNEUR OSCI.0311-16.2016

Park, H. D., Bernasconi, F., Salomon, R., Tallon-Baudry, C., Spinelli, L., Seeck, M., ... Blanke, O. (2018). Neural sources and underlying mechanisms of neural responses to heartbeats, and their role in bodily self-consciousness: An intracranial EEG study. Cerebral Cortex, 28(7), 2351-2364. https://doi.org/10.1093/cercor/bhx136

Park, H.-D., \& Blanke, O. (2019). Coupling inner and outer body for self-consciousness. Trends in Cognitive Sciences, 23(5), 377-388. https://doi.org/10.1016/j.tics.2019.02.002

Parshall, M. B., Schwartzstein, R. M., Adams, L., Banzett, R. B., Manning, H. L., Bourbeau, J., ... American Thoracic Society Committee on Dyspnea (2012). An official American Thoracic Society statement: Update on the mechanisms, assessment, and management of dyspnea. American Journal of Respiratory and Critical Care Medicine, 185(4), 435-452. https://doi.org/10.1164/ rccm.201111-2042ST

Pfeiffer, C., Lopez, C., Schmutz, V., Duenas, J. A., Martuzzi, R., \& Blanke, O. (2013). Multisensory origin of the subjective first-person perspective: Visual, tactile, and vestibular mechanisms. PLoS ONE, 8(4), e61751. https://doi.org/10.1371/journal.pone.0061751
Pouget, P., Allard, E., Poitou, T., Raux, M., Wattiez, N., \& Similowski, T. (2018). Slower is higher: Threshold modulation of cortical activity in voluntary control of breathing initiation. Frontiers in Neuroscience, 12, 663. https://doi.org/10.3389/fnins.2018.00663

Pozeg, P., Galli, G., \& Blanke, O. (2015). Those are your legs: The effect of visuo-spatial viewpoint on visuo-tactile integration and body ownership. Frontiers in Psychology, 6, 1749. https://doi. org/10.3389/fpsyg.2015.01749

Preas, H., Jubran, A., Vandivier, R., Reda, D., Godin, P., Banks, S., ... Suffredini, A. (2001). Effect of endotoxin on ventilation and breath variability: Role of cyclooxygenase pathway. American Journal of Respiratory and Critical Care Medicine, 164(4), 620-626. https:// doi.org/10.1164/ajrccm.164.4.2003031

Quintana, D. S., \& Williams, D. R. (2018). Bayesian alternatives for common null-hypothesis significance tests in psychiatry: A non-technical guide using JASP. BMC Psychiatry, 18, 178. https:// doi.org/10.1186/s12888-018-1761-4

Ranohavimparany, A., Bautin, N., Fiamma, M.-N., Similowski, T., \& Straus, C. (2016). Source of ventilatory complexity in the postmetamorphic tadpole brainstem, Pelophylax ridibundus: A pharmacological study. Respiratory Physiology \& Neurobiology, 224, 27-36. https://doi.org/10.1016/j.resp.2014.11.005

Ronchi, R., Bello-Ruiz, J., Lukowska, M., Herbelin, B., Cabrilo, I., Schaller, K., \& Blanke, O. (2015). Right insular damage decreases heartbeat awareness and alters cardio-visual effects on bodily self-consciousness. Neuropsychologia, 70, 11-20. https://doi. org/10.1016/j.neuropsychologia.2015.02.010

Schmidt, M., Demoule, A., Cracco, C., Gharbi, A., Fiamma, M.-N., Straus, C., ... Similowski, T. (2010). Neurally adjusted ventilatory assist increases respiratory variability and complexity in acute respiratory failure. Anesthesiology, 112(3), 670-681. https://doi. org/10.1097/ALN.0b013e3181cea375

Sharshar, T., Ross, E. T., Hopkinson, N. S., Porcher, R., Nickol, A. H., Jonville, S., ...Polkey, M. I. (2004). Depression of diaphragm motor cortex excitability during mechanical ventilation. Journal of Applied Physiology (Bethesda, Md.: 1985), 97(1), 3-10. https://doi. org/10.1152/japplphysiol.01099.2003

Suzuki, K., Garfinkel, S. N., Critchley, H. D., \& Seth, A. K. (2013). Multisensory integration across exteroceptive and interoceptive domains modulates self-experience in the rubber-hand illusion. Neuropsychologia, 51(13), 2909-2917. https://doi.org/10.1016/j. neuropsychologia.2013.08.014

Tabachnick, B. G., \& Fidell, L. S. (2012). Using multivariate statistics (6th ed.). Boston, MA: Pearson.

Teulier, M., Fiamma, M.-N., Straus, C., \& Similowski, T. (2013). Acute bronchodilation increases ventilatory complexity during resting breathing in stable COPD: Toward mathematical biomarkers of ventilatory function? Respiratory Physiology \& Neurobiology, 185(2), 477-480. https://doi.org/10.1016/j.resp.2012.09.006

Tobin, M. J., Mador, M. J., Guenther, S. M., Lodato, R. F., \& Sackner, M. A. (1988). Variability of resting respiratory drive and timing in healthy subjects. Journal of Applied Physiology (Bethesda, Md.: 1985), 65(1), 309-317. https://doi.org/10.1152/ jappl.1988.65.1.309

Tsakiris, M. (2010). My body in the brain: A neurocognitive model of body-ownership. Neuropsychologia, 48(3), 703-712. https://doi. org/10.1016/j.neuropsychologia.2009.09.034

Wagenmakers, E.-J., Love, J., Marsman, M., Jamil, T., Ly, A., Verhagen, J., ... Morey, R. D. (2018). Bayesian inference for psychology. 
Part II: Example applications with JASP. Psychonomic Bulletin \& Review, 25(1), 58-76. https://doi.org/10.3758/s13423-017-1323-7

Wilkinson, L. (1999). Statistical methods in psychology journals: Guidelines and explanations. American Psychologist, 54(8), 594 604. https://doi.org/10.1037/0003-066X.54.8.594

Wysocki, M., Cracco, C., Teixeira, A., Mercat, A., Diehl, J.-L., Lefort, Y., ... Similowski, T. (2006). Reduced breathing variability as a predictor of unsuccessful patient separation from mechanical ventilation. Critical Care Medicine, 34(8), 2076-2083. https://doi. org/10.1097/01.CCM.0000227175.83575.E9

Wysocki, M., Meshaka, P., Richard, J.-C., \& Similowski, T. (2004). Proportional-assist ventilation compared with pressure-support ventilation during exercise in volunteers with external thoracic restriction. Critical Care Medicine, 32(2), 409-414. https://doi. org/10.1097/01.CCM.0000108869.12426.51

\section{SUPPORTING INFORMATION}

Additional supporting information may be found online in the Supporting Information section.

TABLE S1 Results of separate mixed-effects model for repeated-measures ANOVA run for each item, in order to evaluate the effect of synchronicity and (mechanical ventilation) mode ( $p$ values $<.05$ are represented in bold)

TABLE S2 Results of a Bayesian repeated-measures ANOVA run on run for each item, in order to explore the effect of synchronicity and (mechanical ventilation) mode. Each model was compared to the null model (model only including subjects). A Bayes Factor (BF) below 1/3 provides substantial evidence towards the null hypothesis (i.e., preference of the null model over the effect model; with $1 / 10<\mathrm{BF}<1 / 3=$ moderate evidence; $\mathrm{BF}<1 / 10=$ strong evidence) whereas a $\mathrm{BF}$ above 3 shows compelling evidence towards the alternative hypothesis (i.e., preference of the effect model over the null model; with $3<\mathrm{BF}<10$ $=$ moderate evidence; $\mathrm{BF}>10=$ strong evidence). $\mathrm{A} \mathrm{BF}$ between 3 and 1/3 implies there is not enough evidence in either direction

TABLE S3 Results of a mixed-effects model for repeated-measures ANOVA run on Mental Ball Dropping task reaction time differnces, in order to evaluate the effect of synchronicity and mode ( $p$ values $<.05$ are represented in bold)

How to cite this article: Betka S, Canzoneri E, Adler D, et al. Mechanisms of the breathing contribution to bodily self-consciousness in healthy humans: Lessons from machine-assisted breathing?. Psychophysiology. 2020;57:e13564. https://doi. org/10.1111/psyp.13564 